\title{
Early steps of microglial activation are directly affected by neuroprotectant FK506 in both in vitro inflammation and in rat model of stroke
}

\author{
Malgorzata Zawadzka • Michal Dabrowski • \\ Agata Gozdz • Barbara Szadujkis • Marcin Sliwa • \\ Maciej Lipko • Bozena Kaminska
}

Received: 28 December 2011 /Revised: 10 May 2012 / Accepted: 30 May 2012 / Published online: 18 July 2012

(C) The Author(s) 2012. This article is published with open access at Springerlink.com

\begin{abstract}
Neuroprotective and/or neuroregenerative activity of FK506, its derivatives, and to a lesser extent cyclosporin A (CsA) in animal models of neurodegenerative diseases of different etiology have been reported. Here, we verified a hypothesis that the most likely mechanism of their neuroprotective action is inhibition of the early steps of inflammatory activation of microglia by interference with mitogen-activated protein kinase (MAPK) signaling. The effect of immunosuppressants on lipopolysaccharide (LPS)-induced changes in morphology, proliferation, and motility of rat primary microglial cultures was evaluated. FK506 and CsA directly inhibited LPS-induced microglia activation and inflammatory responses. While both drugs efficiently reduced the expression of iNOS and the release of nitric oxide, only FK506 strongly inhibited the expression of Cox-2 and secretion of the mature form of IL-1 $\beta$. FK506 strongly reduced LPS-induced activation of MAPK, and its downstream signaling crucial for inflammatory responses. Comparative analysis of global
\end{abstract}

Electronic supplementary material The online version of this article (doi:10.1007/s00109-012-0925-9) contains supplementary material, which is available to authorized users.

M. Zawadzka • M. Dabrowski · A. Gozdz • B. Szadujkis •

M. Sliwa $\cdot$ M. Lipko $\cdot$ B. Kaminska

Laboratory of Transcription Regulation, Department Cell Biology,

Nencki Institute of Experimental Biology,

3 Pasteur Str.,

02-093 Warsaw, Poland

B. Kaminska $(\bowtie)$

Laboratory of Transcription Regulation,

Nencki Institute of Experimental Biology,

3 Pasteur Str.,

02-093 Warsaw, Poland

e-mail: bozenakk@nencki.gov.pl gene expression in rat ischemic brains and in LPSstimulated microglial cultures revealed many genes and signaling pathways regulated in the same way in both systems. FK506 treatment blocked a majority of genes induced by an ischemic insult in the cortex, in particular inflammatory/innate immunity and apoptosis-related genes. Microglia-mediated inflammation is considered as one of the most important components of brain injury after trauma or stroke; thus, effective and multifaceted blockade of microglial activation by FK506 has clinical relevance and potential therapeutic implications.

Keywords CNS inflammation · Microglia activation · Immunosuppressants · MAPK signaling · Gene expression profiling

\section{Introduction}

Microgliosis is one of the most important components of poststroke neuroinflammation which is also accompanied by astrogliosis, and manifests in local inflammation, infiltration of immune cells, and activation of the adaptive immunity [1]. In response to brain injury or infection, intracellular signaling pathways are activated in microglia, which turn on inflammatory and antigen-presenting cell functions. Acute activation of microglia can contribute to neuronal damage by production of cytotoxic and inflammation mediators such as nitric oxide, reactive oxygen species, prostaglandin products, pro-inflammatory cytokines IL- $1 \beta$, tumor necrosis alpha (TNF- $\alpha$ ), IL-2, IL-6, or by autoimmune mechanisms $[2,3]$. Clinical and experimental data showed a detrimental role of inflammatory cytokines in injured brain, and inhibition of IL- $1 \beta$ and TNF- $\alpha$ activity 
with neutralizing antibodies or soluble receptors decreased neuronal damage in animal models of stroke $[4,5]$.

Numerous studies have reported neuroprotective and/or neuroregenerative activity of immunosuppressant FK506, its derivatives, and to a lesser extent cyclosporin A (CsA) in animal models of neurological diseases of different etiology: traumatic brain injury, spinal cord injury, optic nerve crush, antiretroviral toxic neuropathy, rodent models of Parkinson's disease, and stroke [6-8]. Therapeutic time window of FK506 is narrow: $2-3 \mathrm{~h}$ in the rat middle cerebral artery occlusion (MCAo) model. In the nonhuman primate stroke model, drug administration $2 \mathrm{~h}$ after the ischemic insult significantly reduced neurological deficits and infarct volumes in the cerebral cortex. Administration of FK506 $4 \mathrm{~h}$ after the insult showed significant amelioration of neurological deficits, suggesting a therapeutic time window for FK506 comparable with 3-4.5 h reported for a tissue plasminogen activator (rt-PA, alteplase) [9]. FK506 exerts multiple types of action, such as inhibition of apoptotic and necrotic cell death in cultured neurons, attenuation of leukocyte accumulation, and attenuation of glia activation $[10,11]$. It suggests the drug's interference with cellular processes which are common to many neuropathological conditions, and a mechanistic pathway for its neuroprotective effect in vivo needs to be explored.

We have previously demonstrated that FK506 administered $1 \mathrm{~h}$ after transient MCAo reduced microglia activation as well as hypertrophy of astrocytes in the ischemic penumbra, ameliorating brain damage and neurological deficits [12]. Recently, we performed global gene expression profiling and the functional analysis of the genes affected after MCAo in rats revealed that the ten significantly overrepresented gene categories include "response to wounding" and "inflammatory response" [13]. This may represent gene induction in activated microglia as the early expression of inflammatory cytokines in the ischemic brain has been demonstrated predominantly in microglia [12]. Thus, we hypothesized that FK506 may act by blocking initiation of microglial inflammatory responses.

In the present study, we demonstrate that FK506 is a potent inhibitor of microglial activation and production of inflammation mediators. It likely interferes with activation of mitogen-activated protein kinases (MAPK) and nuclear factor kappa B (NFkB) signaling pathways, crucial for regulation of inflammatory gene expression. We identified an inflammatory gene signature common for lipopolysaccharide (LPS)-stimulated microglial cultures and ischemic brain, and demonstrated the inhibitory effect of FK506 on the expression of numerous genes related to inflammatory response and cell death in a rat model of stroke. We postulate that pharmacological intervention with FK506 may be a good therapeutic strategy targeting the inflammatory component of stroke.

\section{Methods}

Cell culture and treatment

Primary cultures of rat microglia were prepared as described [14]. Briefly, cells were isolated from cerebral cortices and plated at the density of $3 \times 10^{5}$ cells $/ \mathrm{cm}^{2}$ in culture medium (DMEM/Glutamax/high glucose, Gibco, $10 \%$ FBS, $100 \mathrm{U} / \mathrm{mL}$ penicillin, and $0.1 \mathrm{mg} / \mathrm{mL}$ streptomycin) on poly-L-lysine-coated culture flasks. After 2 weeks of culture, the loosely adherent microglial cells were recovered from confluent glial cultures by a mild shaking and centrifugation. Cells were suspended in the culture medium and plated at density of $3 \times 10^{5}$ cells $/ \mathrm{cm}^{2}$ onto 24 -well plates or $60-\mathrm{mm}$ dishes. Nonadherent cells were removed after $30 \mathrm{~min}$ by changing the medium. Adherent cells ( $>96 \%$ positive for isolectin $\mathrm{B}_{4}$ ) were incubated for $48 \mathrm{~h}$. Cells were stimulated with $100 \mathrm{ng} / \mathrm{mL}$ LPS from Salmonella enteritidis (Sigma, Germany). Compounds were added 30 min before LPS stimulation. FK506 (LC Laboratories, Woburn, MA, USA) was diluted in ethanol; control cells received an equal amount of ethanol. Cyclosporin A (Sandimmune, Novartis, Basel, Switzerland) was diluted in a culture medium.

\section{Immunocytochemistry}

For immunocytochemistry, cells were fixed with $4 \%$ paraformaldehyde at indicated time points after treatment. Next, cells were incubated with fluorescein isothiocyanate (FITC)-conjugated isolectin $\mathrm{B}_{4}$ from Bandeiraea simplicifolia $(10 \mu \mathrm{g} / \mathrm{mL}$, Sigma, Germany) for $4 \mathrm{~h}$ at room temperature and counterstained with DAPI (4',6-diamidino-2phenylindole, Sigma, Germany, $10 \mu \mathrm{g} / \mathrm{mL}$ ). The effects of the compounds were monitored by fluorescent microscopy (450-490 nm). Ten randomly distributed visual fields were captured for each experimental condition used in three independent experiments. Cell body area was measured using ImageJ software (NIH, http://rsb.info.nih.gov/ij/).

Proliferation and cell motility assays

Microglial proliferation was determined by BrdU incorporation assay in cell cultures exposed to various treatments (untreated, $100 \mathrm{ng} / \mathrm{mL}$ LPS alone, or with immunosuppressant). After $18 \mathrm{~h}$, BrdU $(10 \mu \mathrm{M})$ was added to the culture medium for $6 \mathrm{~h}$, and subsequently, cells were fixed, and the level of BrdU incorporation was estimated according to the manufacturer's protocol (Roche, Mannheim, Germany).

For motility assay, cells were plated on a $35-\mathrm{mm}$ Petri dish, and the cultures were gently scratched using a $100-\mu l$ pipette tip. After washing with phosphate-buffered saline (PBS), cells were left untreated or were exposed for $6 \mathrm{~h}$ to LPS alone or in combination with $5 \mu \mathrm{M}$ FK506 or CsA. The 
cells were fixed and cell nuclei were stained with DAPI. Cells from more than three representative fields for every treatment were counted using ImageJ software.

Evaluation of IL-1 $\beta$ and nitric oxide production

Microglia were stimulated with LPS alone or in combination with immunosuppressants. Twenty-four hours after stimulation, the culture media were collected, centrifuged at $500 \times g$ for $10 \mathrm{~min}$, and the supernatants were used for determination of $\mathrm{NO}$ and cytokine production. NO production was assessed with the NO release assay (Active Motif, Rixensart, Belgium). IL- $1 \beta$ production was measured by ELISA using rat-specific antibody pairs and rat protein standards in accordance with the manufacturer's instructions (R\&D Systems, Wiesbaden, Germany). Cytokine levels were calculated as nanograms per milliliter and expressed as a percentage of the IL-1 $\beta$ release in control cultures.

Protein isolation, electrophoresis, and detection

Whole-cell protein extracts were separated on SDS-PAGE and transferred onto a nitrocellulose membrane (Amersham Biosciences, Germany). Antibodies recognizing phosphorylated forms of p38, p44/42 MAP kinase (ERK1/2), JNK, MAPKAP-2, c-Jun, and IKB as well as Cox-2 $(1: 1,000)$ were purchased from Cell Signaling Technology (Beverly, MA, USA), inducible NO synthase (iNOS; diluted 1:2,000) was from BD Biosciences (Bedford, MA, USA) and IL-1 $\beta$ (diluted 1:1,000) from Santa Cruz Biotechnology (Santa Cruz, CA, USA). Immunocomplexes were visualized by using ECL (Amersham). To verify equal amounts of protein loading, the membranes were reprobed with anti- $\beta$-Actin antibody (diluted 1:2,000, from Oncogene Research Products, MA, USA).

Transient middle cerebral artery occlusion and RNA extraction

MCAo was induced for 90 min with the intraluminal filament method as described $[12,13]$. The procedure resulted in ischemic damage in the frontoparietal somatosensory cortex, striatum, and other areas such as hypothalamus, corresponding to the territory supported by the middle cerebral artery (MCA). FK506 (Tacrolimus, Fujisawa, UK) was administrated intravenously at $1 \mathrm{mg} / \mathrm{kg}$ body weight $60 \mathrm{~min}$ after MCAo. FK506 significantly reduced tissue damage in the cerebral cortex by $63 \%$ as assessed by TTC staining [12]. Rats were lethally anesthetized at $12 \mathrm{~h}$ of reperfusion, brains were rapidly removed, and the same dorsolateral parts of the cerebral cortex containing MCA territory were dissected. Total RNA was extracted using TRI reagent (Sigma, Germany) and cleaned using RNeasy Total RNA kit (Qiagen, Germany). The amount and quality of the RNA were determined by capillary electrophoresis with the Bioanalyzer 2100 (Agilent Technologies).

Microarray gene expression profiling

Comparative analysis of global gene expression was performed on two experimental paradigms: LPS-stimulated primary microglial cultures (six independent cultures for the control conditions and four RNA samples for LPStreated cultures) and brain ischemia induced by middle cerebral artery occlusion (sham-operated (S) and MCAosubjected rats with $(\mathrm{F})$ or without $(\mathrm{M})$ treatment with FK506, $n=3$ ).

Biotin-labeled cRNAs were synthesized with the Affymetrix IVT labeling kit. Fragmented cRNA was hybridized first to a control microarray and then, after sample quality evaluation, was hybridized to the Affymetrix GeneChip Rat Genome 230-2.0 Gene Chips (31,042 probe sets including 28,000 rat genes).

Microarray data were preprocessed with the MAS 5.0 algorithm, as implemented in the "affy" R Bioconductor package [15]. Only consistently detected probesets in all hybridizations for at least one condition in a given experiment (call: Present or Marginal) were mapped to Ensembl 57 gene identifiers (gene_stable_id). For each gene, we computed a single average intensity profile from the profiles of all the probesets mapped to it. The resulting average profile was then $\log _{2}$-transformed and used in statistical analysis and visualization.

In the MCAo model, we used one-way ANOVA to identify the genes that changed expression among the three conditions (S, M, and F). We used unpaired Student's $t$ test, with Welch's approximation for the degrees of freedom, to identify genes with significantly different mean expression between the contrasted groups ( $\mathrm{S}$ vs. M, M vs. F). In the in vitro experiment, we used paired $t$ test to identify genes with mean difference in expression, between the control and LPS for matched microglia preparations, significantly different from zero. For the false discovery rate (FDR) analysis, the lists of $p$ values were imported into $\mathrm{R}$ statistical environment (http://www.R-project.org), and the $q$ values [16] were calculated using the R "qvalue" package. To identify functional Gene Ontology categories associated with the observed changes in expression, the lists of gene symbols (Ensembl display_id) of the genes with the respective $t$ test $p$ value $<$ 0.05 were ranked on the difference in $\log _{2}$ expression, either $\mathrm{M}$ minus $\mathrm{S}$, or $\mathrm{F}$ minus $\mathrm{M}$, and for LPS microglia minus control, and analyzed using Rank GOstat [17] with the default options (Wilcoxon signed rank test, Benjamini false discovery rate correction for multiple testing).

The datasets from both experiments were submitted to ArrayExpress, and are available with the following 
accession numbers: E-MEXP-2222 (MCAo) and E-MEXP2466 (microglia).

\section{Statistical analysis}

In vitro experiments were performed on at least three independently derived primary microglial cultures, in triplicates. Statistical analysis was carried out using one-way analysis of variance (ANOVA) followed by post hoc Newman-Keuls test with STATISTICA software (StatSoft, Tulsa, OK, USA). Statistical significance was determined at three levels: ${ }^{*} p<0.05,{ }^{* *} p<0.01$, and ${ }^{* * *} p$ $<0.001$. The results are expressed as the mean \pm standard deviation (SD) or the mean \pm standard errors of the mean (SEM) is indicated.

\section{Results}

Immunosuppressants inhibit morphological changes and motility of activated microglia

In response to LPS, microglia undergo activation, which includes morphological transformation, increased motility, phagocytosis, and inflammatory gene expression. We analyzed an influence of FK506 and CsA on LPSinduced changes in morphology and behavior of the rat primary microglial cultures. Untreated microglial cells have bipolar or rod-shape morphology with few short processes ( $3 \%$ of cells with $2,000 \mu \mathrm{m}^{2}$ or larger cell body area), and exposure to LPS for $24 \mathrm{~h}$ resulted in cell body enlargement (62\% of cells with $\geq 2,000 \mu \mathrm{m}^{2}$ cell body area) and amoeboid morphology. Treatment with immunosuppressants reduced LPSinduced morphological transformation of microglia by $26 \%$ (in case of $5 \mu \mathrm{M}$ FK506) or $70 \%(5 \mu \mathrm{M} \mathrm{CsA})$ (Fig. 1a). The inhibitory effect was more prominent at higher drug concentrations $(10 \mu \mathrm{M}$ FK506 and CsA, data not shown).

LPS inhibited microglial cell division in both mixed astrocyte/microglia cultures and in microglial cultures. To study if immunosuppressants could affect LPS-induced growth arrest, we assessed microglial proliferation (by measuring of BrdU incorporation) $24 \mathrm{~h}$ after treatment with LPS alone or with drugs. FK506 and CsA did not interfere with LPS-induced growth arrest, as shown in Fig. 1b.

Motility of microglial cells was examined with a scratch assay. The untreated microglial cells exhibit weak motility, only few cells migrated into the scratch area. Prominent induction of cell migration was observed in cultures treated with LPS. Immunosuppressants at concentration of $5 \mu \mathrm{M}$ completely abolished LPS-induced cell motility (Fig. 1c).
FK506 and CsA differentially modulate LPS-induced production of inflammation mediators

We evaluated effects of immunosuppressants on the levels of IL- $1 \beta$, NO, and Cox- 2 produced by microglia. IL- $1 \beta$ protein level was assessed by Western blotting and ELISA. Increase of pro-IL-1 $\beta(31 \mathrm{kDa})$ level was detected in microglial cells $1 \mathrm{~h}$ after LPS addition and gradually elevated up to $12 \mathrm{~h}$ posttreatment (Fig. 2a), when the mature form of IL$1 \beta(17 \mathrm{kDa})$ was detected. Pretreatment with FK506 reduced accumulation of the mature IL- $1 \beta$ in a dosedependent manner (Fig. 2b). The results were corroborated by ELISA. Untreated cells produced $0.24 \pm 0.03 \mathrm{ng} / \mathrm{mL}$ IL$1 \beta$, while upon activation the cytokine concentration reached $1.5 \pm 0.2 \mathrm{ng} / \mathrm{mL}$ (Fig. 2c). Treatment with $20 \mu \mathrm{M}$ FK506 decreased LPS-dependent cytokine secretion to $0.44 \pm 0.1 \mathrm{ng} / \mathrm{mL}$. In contrast, low doses of CsA had no effect on IL- $1 \beta$ secretion, while $20 \mu \mathrm{M}$ CsA strongly elevated IL- $1 \beta$ secretion up to $8.71 \pm 1.98 \mathrm{ng} / \mathrm{mL}$.

The iNOS expression was significantly upregulated in LPS-activated microglia (Fig. 3a), and accordingly, NO production increased from $1.43 \pm 0.57 \mu \mathrm{M}$ in untreated cells up to $22.6 \pm 0.82 \mu \mathrm{M}$ in LPS-stimulated cultures (15.8-fold induction). Treatment with CsA or FK506 significantly decreased LPS-induced iNOS expression and NO production (Fig. 3a, b). FK506 was more potent than CsA and reduced the LPS-induced NO

Fig. 1 FK506 and CsA attenuate LPS-induced transformation of microglia. a Primary microglial cultures were prepared as described and kept for $48 \mathrm{~h}$ after plating to silence microglia. Morphological alterations of microglia untreated or exposed to $100 \mathrm{ng} / \mathrm{mL}$ LPS alone or with immunosuppressants (at concentration of $5 \mu \mathrm{M}$ ) for $24 \mathrm{~h}$ were visualized by immunofluorescence. Cells were stained with FITCconjugated isolectin $\mathrm{B}_{4}$ (green) to visualize cell morphology followed by staining with DAPI for nuclei visualization (blue); $\times 20$ objective. Stained cells with a specified range of size and optical density above fixed threshold value were automatically recognized and counted. Cell body area of microglial cells was measured, and the percentage of cells with body area $>2,000 \mu^{2}$ (activated cells) was calculated. Left panel shows the histograms representing the distribution of microglial cells body area (square micrometers) for all analyzed experimental conditions. Data are expressed as means $\pm \mathrm{SD}$ from ten fields for all treatments in three independent experiments. b FK506 and CsA do not inhibit LPS-induced growth arrest of microglial cells. Microglial proliferation was determined with BrdU incorporation assay $24 \mathrm{~h}$ after treatment. The results are means \pm SEM of three independent experiments, each in triplicate. c Immunosuppressants affect migration of activated microglia. Confluent microglial cultures were scratched with a plastic $100-\mu \mathrm{L}$ tip, washed with PBS, and incubated for $5 \mathrm{~h}$ under given conditions. Cells migrating to a cell-free area without the treatment, after addition of $100 \mathrm{ng} / \mathrm{mL}$ LPS alone or with immunosuppressants $(5 \mu \mathrm{M})$, were visualized by phase-contrast microscopy (magnification $\times 4$ ). Left panel shows quantitative evaluation of motility/migration of microglia treated with LPS alone or with immunosupressants at $6 \mathrm{~h}$ time point. Cells from five fields between scratch edges along the line were counted. Results represent means \pm SD from two independent experiments each in triplicate 

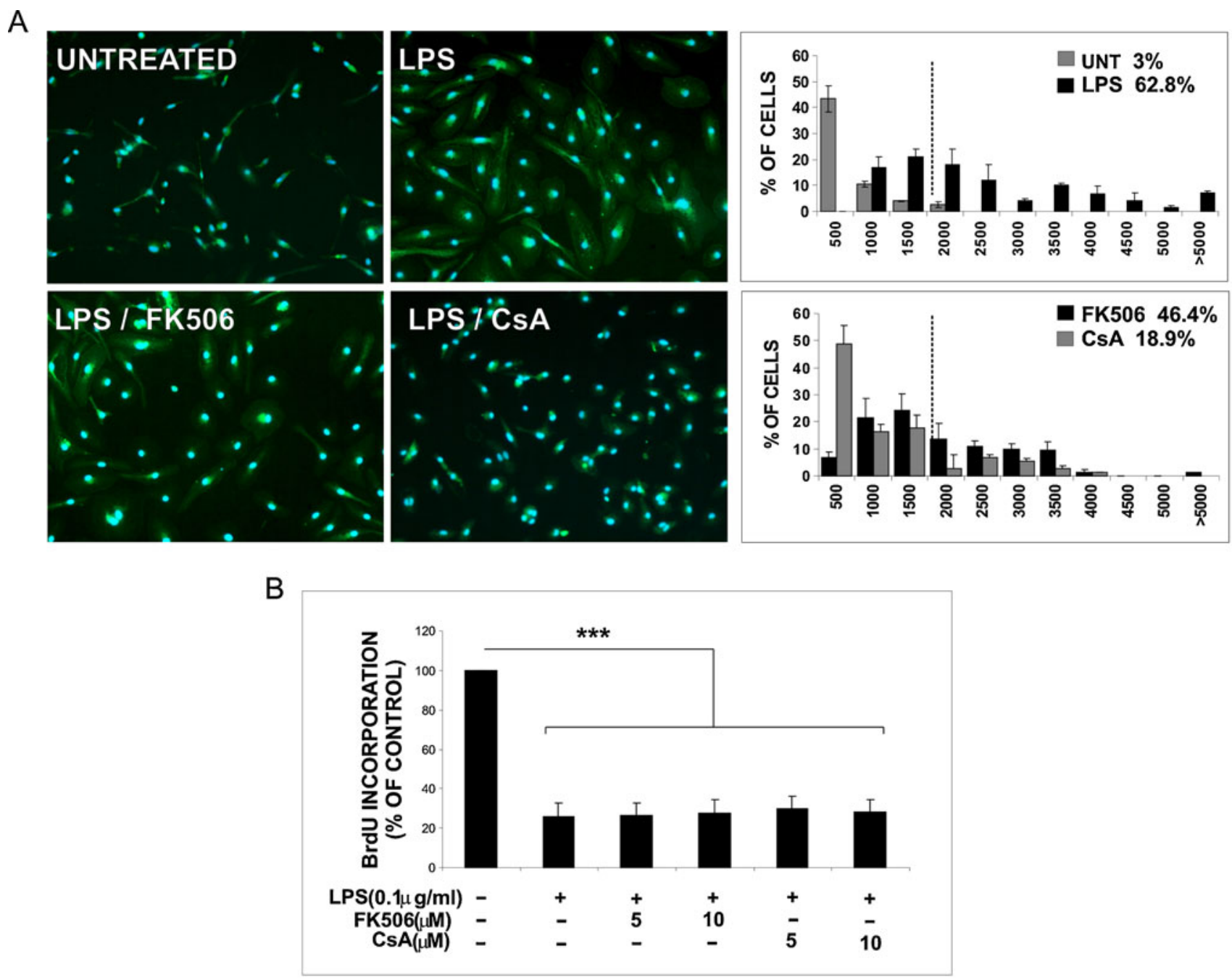

C
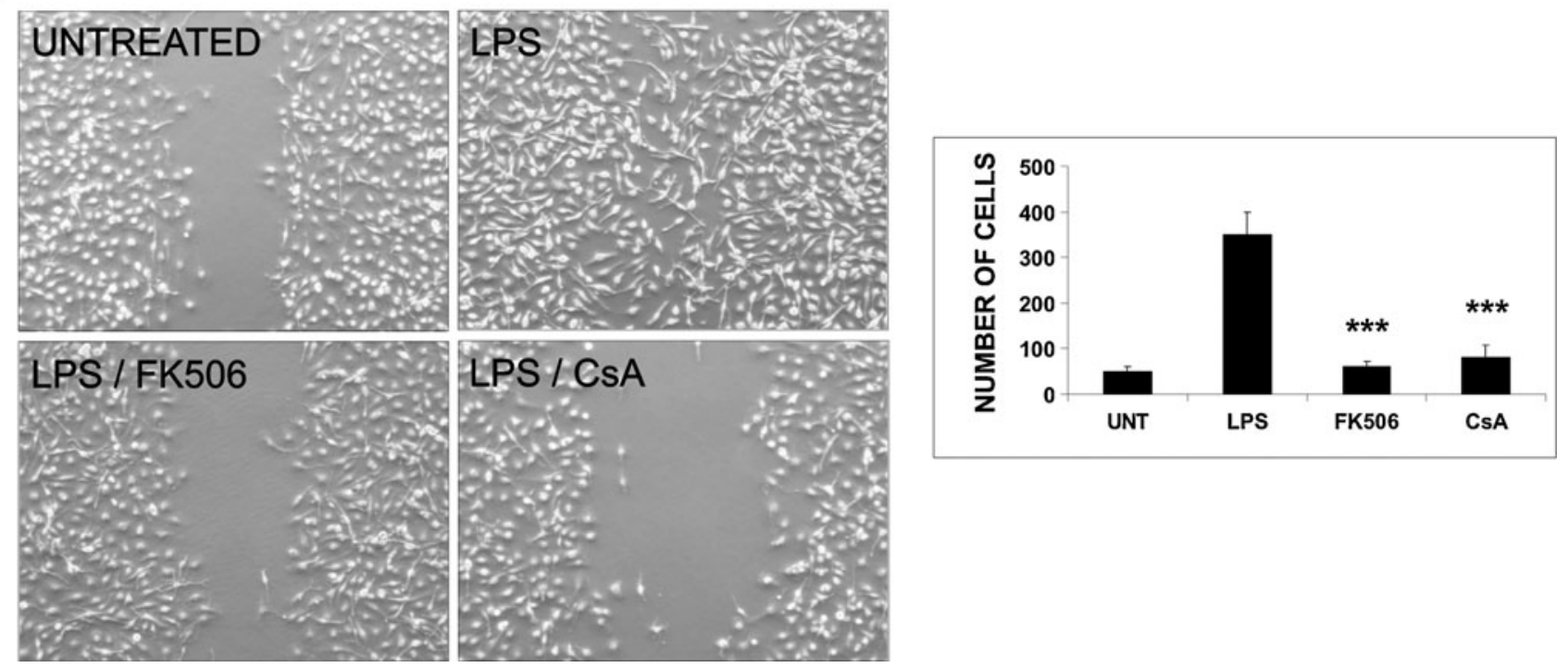
Fig. 2 FK506 reduces LPSinduced production of IL- $1 \beta$ by microglial cells. a Kinetics of LPS-induced production of IL$1 \beta$. Immunoblot shows the levels of pro-IL-1 $\beta(31 \mathrm{kDa})$ and mature IL-1 $\beta(17 \mathrm{kDa})$ protein in extracts from microglial cells at different times after treatment with $100 \mathrm{ng} / \mathrm{mL}$ LPS. $\beta$-Actin detection ensured an equal protein loading. Similar results were observed on three independently derived microglial cultures. b Attenuation of LPS-induced production of the mature form of IL-1 $\beta$ in cells exposed to 5 and $20 \mu \mathrm{M}$ FK506 for $12 \mathrm{~h}$. $\mathbf{c}$ Effects of immunosuppressants on IL- $1 \beta$ secretion by LPS-stimulated microglial cultures evaluated by ELISA assay at $12 \mathrm{~h}$ after treatment. Results are expressed as percentage of the IL- $1 \beta$ release obtained in untreated cells; means \pm SEM from three experiments (each in triplicate) are presented
A

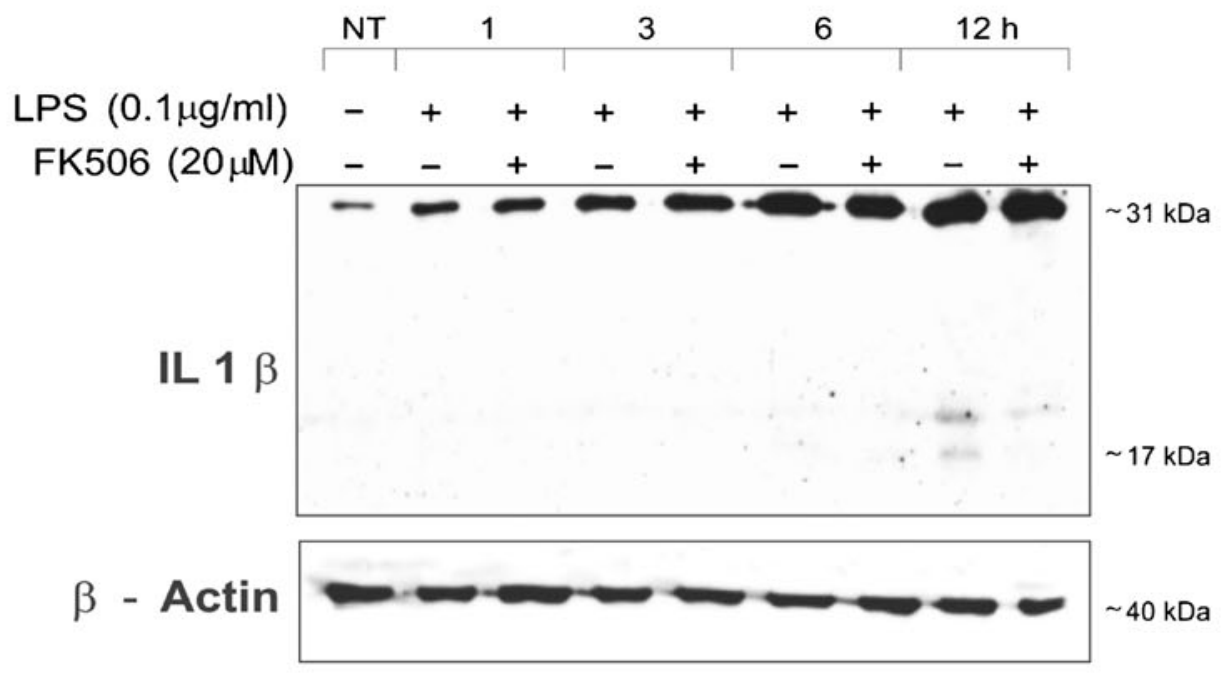

B
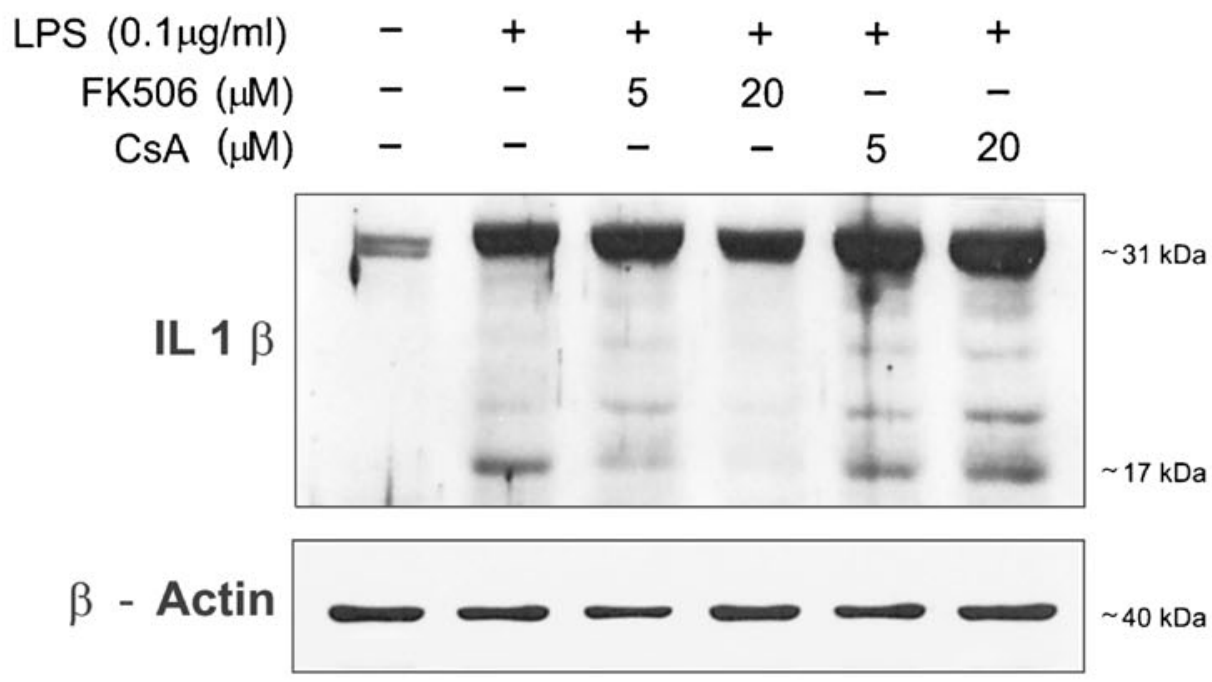

C

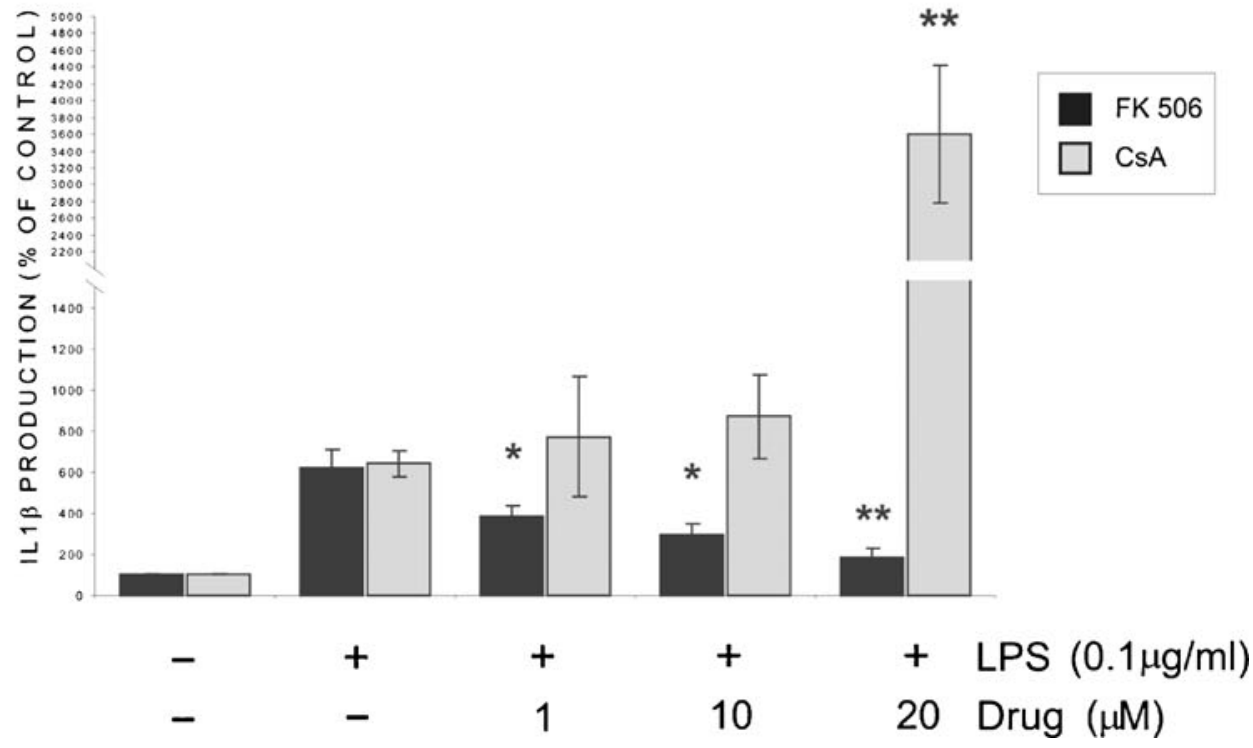




\section{A}

$\begin{array}{rllllll}\mathrm{LPS}(0.1 \mu \mathrm{g} / \mathrm{ml}) & - & + & + & + & + & + \\ \mathrm{FK} 506(\mu \mathrm{M}) & - & - & 5 & 10 & - & - \\ \mathrm{CsA}(\mu \mathrm{M}) & - & - & - & - & 5 & 10 \\ \text { iNOS } & & & & & & \end{array}$

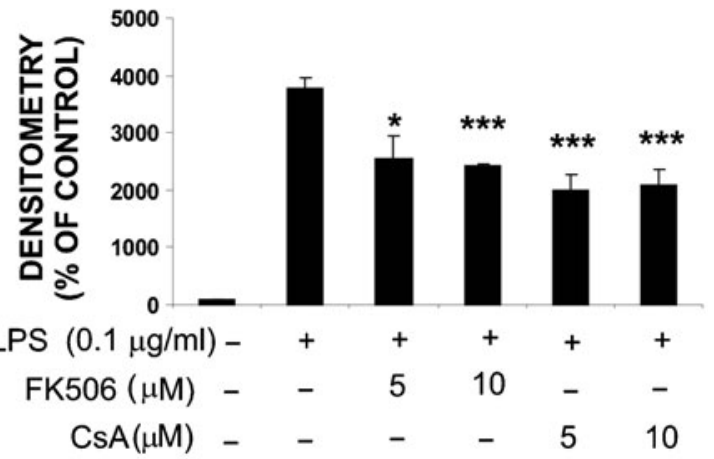

B

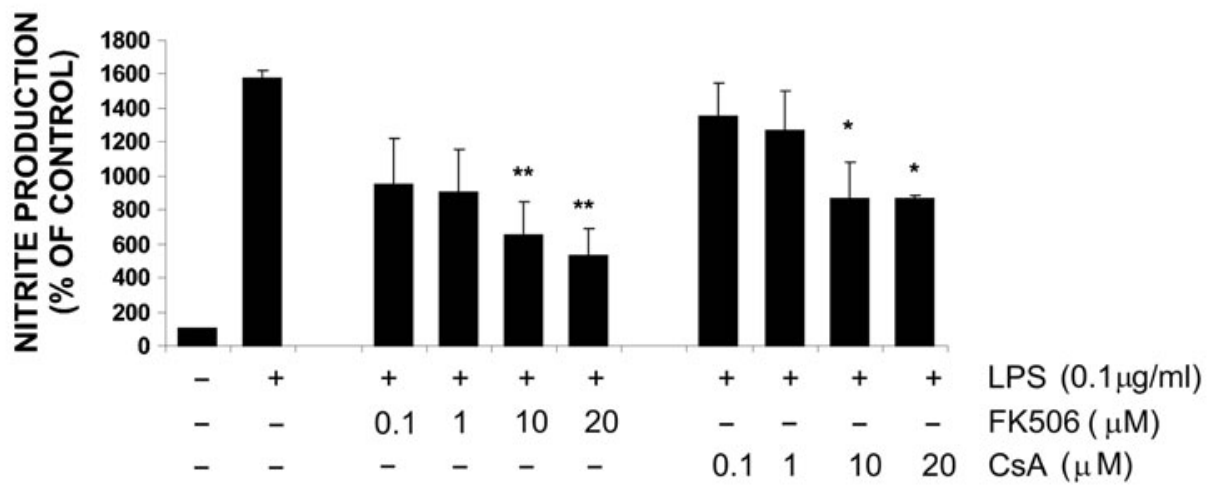

C

$\begin{array}{rcccccc}\operatorname{LPS}(0.1 \mu \mathrm{g} / \mathrm{ml}) & - & + & + & + & + & + \\ \text { FK506 }(\mu \mathrm{M}) & - & - & 5 & 10 & - & - \\ \operatorname{CsA}(\mu \mathrm{M}) & - & - & - & - & 5 & 10\end{array}$
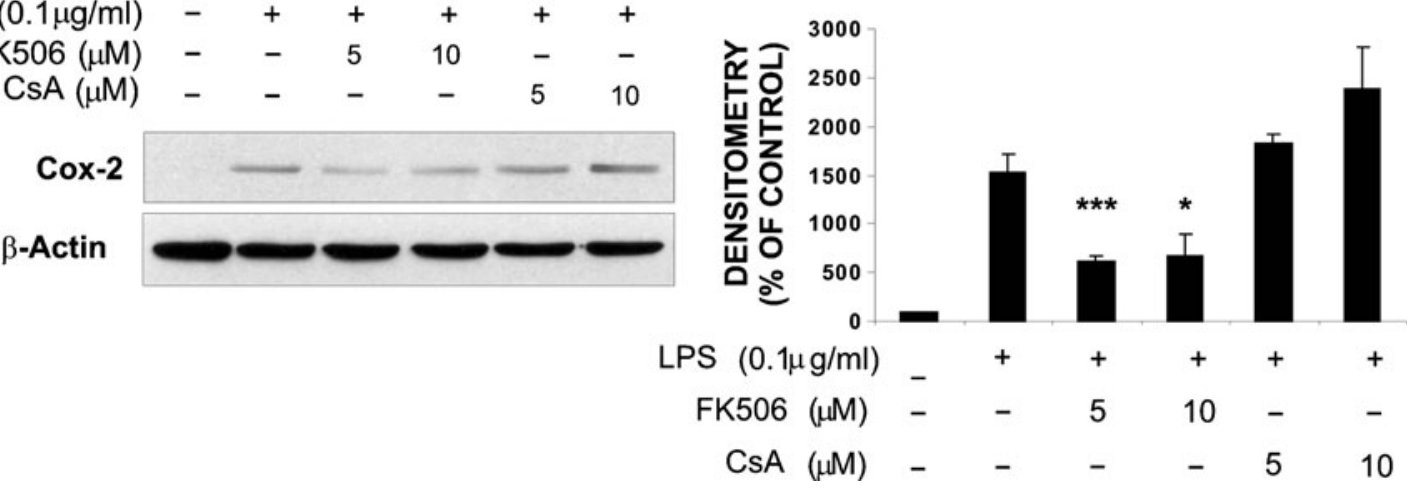

Fig. 3 Immunosuppressants affect LPS-induced production of inflammatory mediators in rat microglial cultures. a Immunoblot shows that FK506 and CsA reduce the level of iNOS protein in microglial cells exposed for $24 \mathrm{~h}$ to $100 \mathrm{ng} / \mathrm{mL}$ LPS alone or together with FK506 or CsA $(5$ or $10 \mu \mathrm{M})$. Densitometry of immunoblots from three independent experiments was performed. The level of iNOS expression was normalized to $\beta$-actin content. All values are related to untreated controls and presented as the mean values \pm SEM. b Nitric oxide production was determined as nitrite concentration in cell culture supernatants and expressed as percentage of the release by untreated cells. Results represent means \pm SEM obtained from three independently derived cultures (each in triplicate). c FK506 (but not CsA) reduces LPS-induced expression of Cox-2 protein in microglial cultures. Densitometry of immunoblots from three independent experiments was performed. The level of Cox-2 expression was normalized to $\beta$-actin content, related to controls and presented as means \pm SEM production by 58.42 and $66.34 \%$ at the concentration of 10 and $20 \mu \mathrm{M}$, respectively, while CsA treatment resulted in 44.89 and $45.22 \%$ reduction.

Cox-2 expression strongly upregulated by LPS treatment (Fig. 3c) was reduced by 5 and $10 \mu \mathrm{M}$ FK506. In contrast,
$5 \mu \mathrm{M}$ CsA had no effect and at the higher dose increased the Cox-2 protein expression. Densitometry of immunoblots from three independent experiments confirmed reduction of LPS-induced Cox-2 protein expression in FK506- but not CsA-treated cultures. 
A

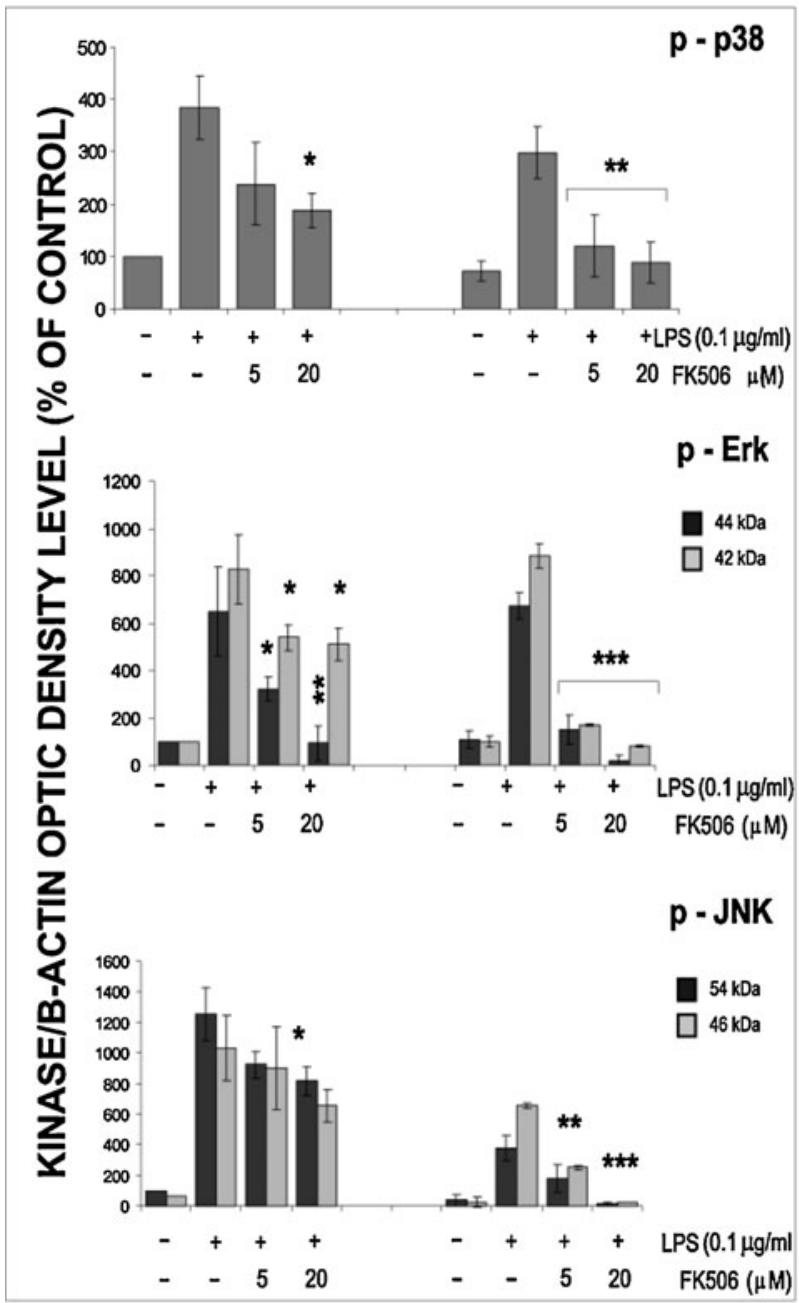

C

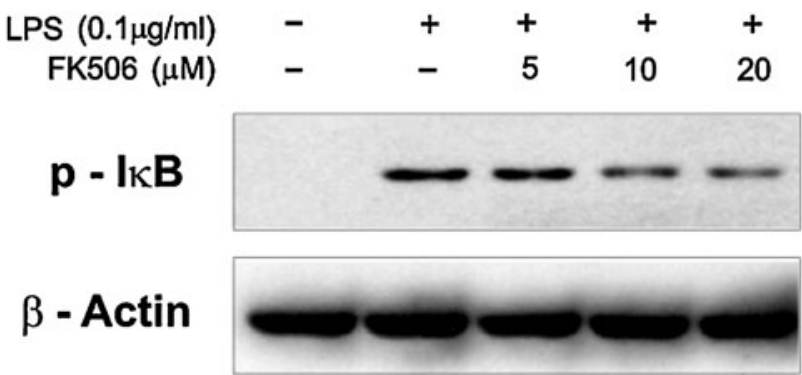

Fig. 4 FK506 interferes with signal transduction triggered by LPS in microglial cultures. Immunoblots show the levels of phosphorylated forms of MAP kinases (a) their substrates, MAPKAPK2 and c-Jun (b) and IKB (c) Western blot analyses were performed with total extracts from microglial cultures treated with LPS alone or with FK506. Similar

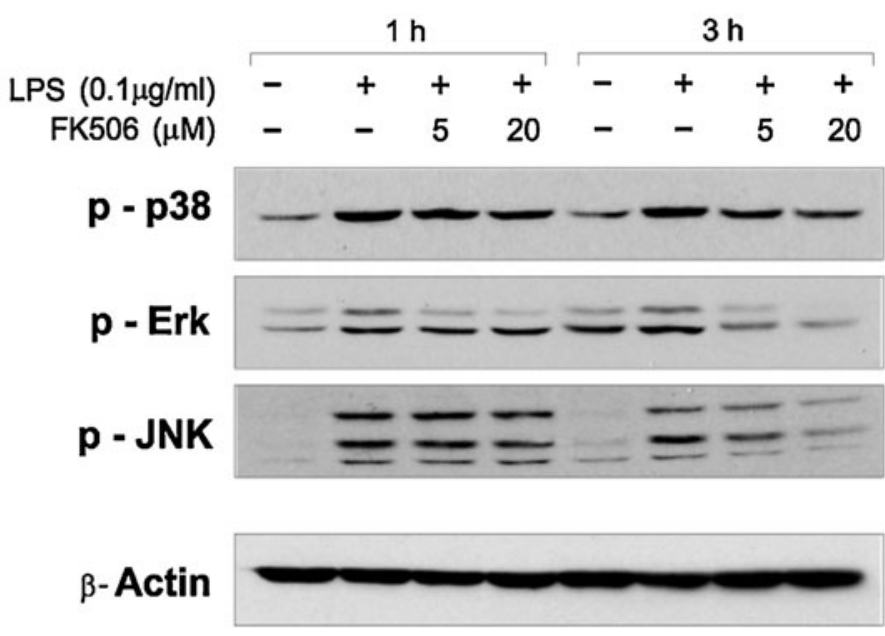

B
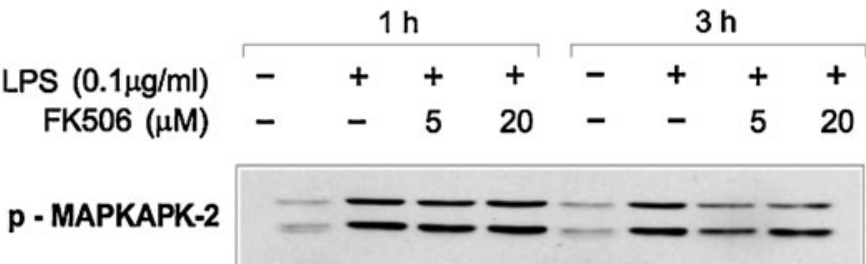

p-c-Jun

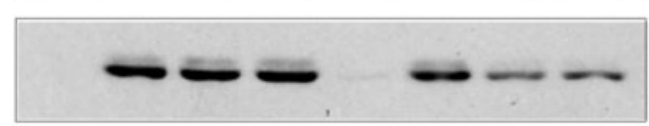

$\beta$ - Actin

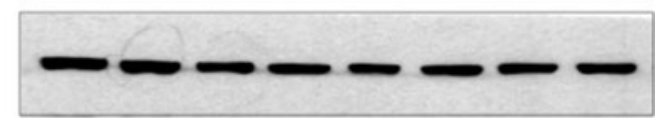

results were obtained in four independent experiments. The level of phosphorylated MAPK was quantified by densitometry, related to the $\beta$-actin level and then to values obtained for untreated microglia. Results are presented as means \pm SEM from three independent experiments 
FK506 affects MAPK signaling in microglia

Three MAPKs were activated shortly after stimulation of microglial cultures with LPS, as shown by Western blotting (Fig. 4a). Treatment with 5 and $10 \mu \mathrm{M}$ FK506 decreased the levels of LPS-induced phosphorylation of MAPK at 1 and $3 \mathrm{~h}$. Densitometry of immunoblots from four independent experiments demonstrated reduction of MAPK phosphorylation in FK506-treated microglial cultures. Concomitantly, LPS-triggered phosphorylation of downstream substrates of p38 and JNK, respectively MAPKAPK-2 and c-Jun, was also decreased by immunosuppressants (Fig. 4b). Moreover, pretreatment with FK506 or CsA inhibited LPS-induced activation of $\mathrm{NF} K \mathrm{~B}$, a key transcriptional regulator of inflammatory response, as assessed by detection of the phosphorylated form of IKB (Fig. 4c). Our results indicate that FK506 impairs activation of MAPK and NFKB signaling in microglial cells that may result in blockade of inflammatory responses.

Inflammation-related genes induced in ischemic brain and LPS-stimulated microglia are blocked by FK506

Since we demonstrated that the expression of crucial inflammatory factors such as IL- $1 \beta$, IL- 6 , and TNF- $\alpha$ reached its maximum in the ipsilateral cortex at $12 \mathrm{~h}$ of reperfusion [12], global gene expression profiling in ischemic cortex has been performed $12 \mathrm{~h}$ after MCAo, MCAo followed by FK506 treatment, or in sham-operated animals, microglial cells were harvested $6 \mathrm{~h}$ of LPS stimulation $(100 \mathrm{ng} / \mathrm{mL})$, at the time point when the expression of inflammation-related genes was upregulated in vitro [18]. For comparisons of the sets of genes regulated by the studied treatments, we choose a uniform $p$ value threshold of 0.05 in order to achieve gene sets of comparable sizes for each treatment. In the ischemic cortex, 1,803 genes significantly changed expression, with the cutoff at $p$ value 0.05 , FDR $q$ value 0.15 , among the 10,404 reliably detected genes. In LPS-treated microglia, 4,949 genes significantly changed its expression, with the cutoff at $p$ value 0.05 , FDR $q$ value 0.03 , among the 9,147 reliably detected genes.

Strong and consistent changes in the expression of similar sets of genes were observed in both systems. Analysis of the ranked list of genes that significantly changed expression $(p<0.05)$ after MCAo, and-separately-in LPStreated microglia, revealed that in both experimental systems, the most affected genes represent similar Gene Ontology (GO) categories, including: "immune system process" and "inflammatory response" (Fig. 5a). Focusing only on genes that significantly changed expression in both models revealed 843 such genes (with $t$ test $p$ values of $<0.05$ in both datasets).
The top panel of Fig. 5b shows relative changes in gene expression induced by LPS in microglial cultures, and by stroke in the ischemic cortex, plotted against each other on the $\log _{2}$ scale. The $\log _{2}$ changes in gene expression in both systems were positively correlated $(r=0.60, d f=841, \quad p$ value $=7.2,10-84)$. The counts of the genes in each quadrant of the top panel of Fig. 5b (a contingency table) are given in Electronic supplementary materials (ESM) Table 3. Given these data, we asked if induction of a gene by LPS in the microglia in vitro predicts induction of the same gene in the cortex following the MCAo. As it turned out, there is a highly significant association between induction in both systems (Fisher's exact test $p$ value $=1.3,10-47$ ). When the induction by LPS was used to predict induction following the MCAo, for all the genes regulated in both systems, the sensitivity and specificity of prediction were 68 and $85 \%$, respectively. However, when the analysis was performed only for the 33 genes that were regulated in both systems and additionally assigned to the GO: inflammatory response term, the sensitivity and specificity of the prediction rose to 94 and $100 \%$, respectively. Thus, for the inflammatory response genes, upregulation by LPS in microglia in vitro accurately predicts upregulation following MCAo.

Majority of those genes, namely 615 , were regulated in the same direction in both systems (dots in the I and III quadrant). Remarkably, 392 genes were upregulated in both systems (dots in the I-st quadrant). Thus, we identified a set of 392 genes upregulated in microglial cultures by LPS treatment that were also upregulated following MCAo. For those genes, the fold changes of expression were similar in both systems (dots scattered around the diagonal $Y=X$ ), and many of them were assigned to the GO category "inflammatory response" (red dots in Fig. 5b). It is likely that those genes were expressed in the same cell type, namely microglia.

FK506 treatment greatly reduced the changes in gene expression induced by MCAo, in particular for the genes that were most strongly induced by MCAo (Fig. 5b, compare top and bottom panel). In the FK506-treated animals, 1,173 genes had significantly different expression, at $p<$ 0.05 , FDR $q$ value $=0.28$, when compared to their expression in the control group (MCAo). Interestingly, most genes induced in ischemic cortex (as compared to sham-operated animals) were downregulated by FK506 treatment. The functional GO categories represented among the genes most strongly downregulated by FK506 were the same as the categories induced by MCAo and included: "response to external stimulus," "response to wounding," "immune system process," and "inflammatory response" (Fig. 5a). Many of the genes affected by the FK506 treatment are assigned to several of these categories (Fig. 5c). Two categories, namely the "inflammatory response" and "immune system process," were also induced by the LPS treatment (Fig. 5a). Validation 
of microarray data by qPCR in independent samples of differently stimulated microglia $(n=3)$ and in vivo experiments ( $n=3-5$ rats) is provided in ESM Fig. 2 . The expression of nine genes, representing the most important targets for FK506 action, chosen on the basis of microarray analysis, has been verified. We confirmed the significant inhibition of inflammation-related gene expression ( $c c l 20$, il6, cxcl2, ccl3, ccl4, ill $\beta$, and stat3) by FK506 treatment (ESM Fig. 2A). Moreover, we validated the same effect of FK506 on LPS-stimulated microglia (ESM Fig. 2B). In both experimental paradigms, FK506 did not significantly affect $b d n f$ expression, as we have previously reported [12]. The results achieved are in accordance with our previously demonstrated data that FK506 administered $1 \mathrm{~h}$ after transient MCAo ameliorated brain damage, reduced microglia activation as well as production of pro-inflammatory cytokine IL-1 $\beta$ in the ischemic penumbra (representative images of FK506 neuroprotective and anti-inflammatory effect are provided in ESM Fig. 3).

\section{Discussion}

The main finding of this study is that FK506 restrains acute inflammatory responses in cultured microglial cells as well as in the ischemic brain. FK506 reduced LPS-induced activation of MAPK and NFKB signaling pathways, affecting crucial steps of microglia activation. This results in inhibition of morphological transformation, motility, and expression of inflammation mediators: IL-1 $\beta$, Cox-2, and iNOS in inflammatory microglia. CsA applied at similar doses mimicked most of FK506 effects but failed to inhibit LPSinduced IL-1 $\beta$ production and Cox- 2 expression. We observed upregulation of IL- $1 \beta$ secretion in cultures treated with $20 \mu \mathrm{M}$ CsA, likely reflecting release of cellular content during CsA-induced cell death as microglial viability was reduced by concomitant treatment with LPS and $20 \mu \mathrm{M}$ CsA (MTT metabolism test, data not shown). Also in naïve microglia, the mature IL-1 $\beta$ production was upregulated by $20 \mu \mathrm{M}$ CsA (ESM Fig. 1). Cox-2 and iNOS expression was barely detectable under basal conditions, and the treatment of naïve, microglial cells with immunosuppressants did not affect their expression.

Our findings emphasize that FK506 is an efficient modulator of inflammatory responses in activated microglia in vitro and likely in vivo. Gene expression profiling revealed that FK506 attenuates global upregulation of "injury" and "inflammation-related" genes in the ischemic brain. Most significantly affected GO functional categories: "response to external stimulus," "response to wounding," and "inflammatory response" could reflect contribution of microglial expression to global genomic responses. The expression of a majority of upregulated inflammation-related genes was almost completely inhibited in FK506-treated ischemic animals.

Interestingly, FK506 strongly affected production of the mature IL-1 $\beta$ and cytokine secretion in microglial cultures. In response to LPS, newly synthesized IL- $1 \beta$ remains mostly cell associated and requires proteolytical processing by a cysteine protease IL- $\beta$-converting enzyme (caspase-1) to generate an active cytokine [19]. Inhibition of externalization or/and proteolytic processing of pro-IL-1 $\beta$ in FK506treated microglial cultures could be a novel mechanism of drug action. However, this may not be a primary event, but a consequence of halting microglia activation. Inhibition of IL-1 $\beta$ activity or signaling with antibodies neutralizing cytokines or soluble cytokine receptors decreased neuronal damage in animal models of stroke [20]. Promising results of IL-1 receptor antagonist delivered peripherally were observed in stroke patients [5].

We show that LPS-induced upregulation of iNOS expression and NO production were inhibited strongly by FK506 and less potently by CsA. Previous results on the macrophage cell line RAW264.7 [21] or murine J774 macrophages suggested that $1-5 \mu \mathrm{g} / \mathrm{mL}$ CsA reduced iNOS expression and NO production, while FK506 was not [22] or less effective [23]. Both immunosuppressants inhibited LPS-induced NO production in rat peritoneal macrophages [24] that is in agreement with our results. We demonstrate that FK506 (but not CsA) significantly reduced LPS-

Fig. 5 FK506 blocks upregulation of numerous inflammation-related genes in the ischemic cortex. a Gene Ontology "biological process" terms most significantly associated with the changes in gene expression induced by MCAo in the ischemic cortex, with or without FK506 treatment, and by LPS activation of microglia in vitro. Analysis was performed on the remote RankGOStat server, with ranked lists of $\log _{2}$ changes in expression of the genes with the respective $t$ test $p$ value $<$ 0.05 used as the input files, and RGD selected as the target database. For the plot, the FDR-corrected association $p$ values were $\log 10$ transformed and signed, i.e., multiplied by +1 or -1 to reflect association with increased or decreased expression, respectively. Numbers of genes in each GO category are given in parentheses. b Comparison of $\log _{2}$ changes in gene expression induced in microglia by LPS and after MCAo for the genes significantly regulated in both systems (top panel). The changes of the same genes as in the top panel are compared to the changes induced by MCAo in the animals that received FK506 (bottom panel). Red dots represent gene assigned to GO: inflammatory response. c. Venn diagram of the genes affected by FK506 treatment assigned to GO categories: "response to external stimulus," "response to wounding," "immune system process," and "inflammatory response." A newer local version of the GO database was used than by the RankGOStat server, resulting in larger numbers of genes assigned to the same GO terms than in (a). For details of the gene names and the expression data, see ESM Table 1. d Heat maps of expression profiles of the genes in GO catagories: "response to wounding" and "inflammatory response" that were regulated by FK506. The genes were sorted on the change in expression induced by MCAo (as compared to sham). The genes that were also significantly regulated during microglia activation with LPS are marked with an asterisk 


\section{A}

sham vs MCAO

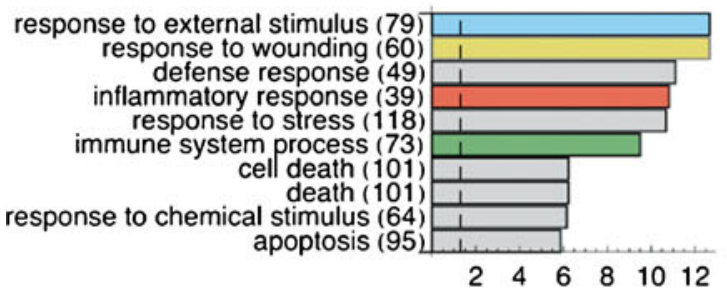

signed

$\log 10$

\section{MCAo vs MCAo+FK506}

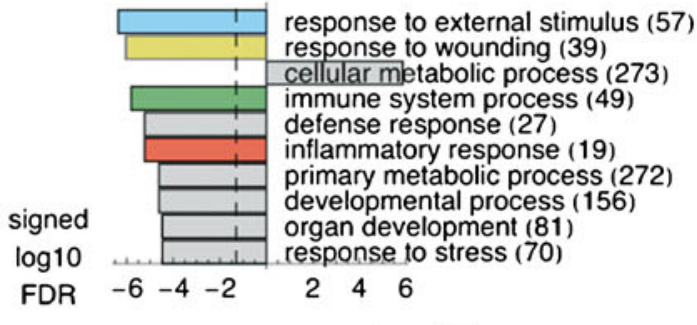

control vs LPS

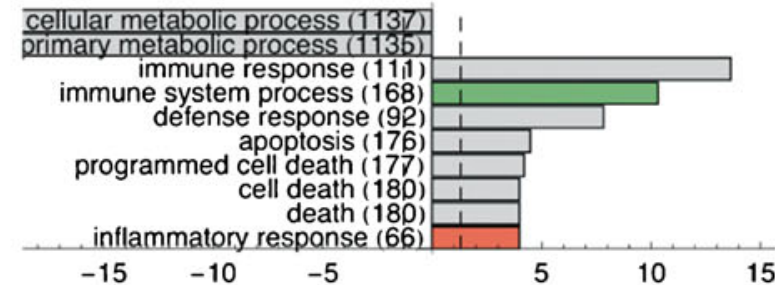

C

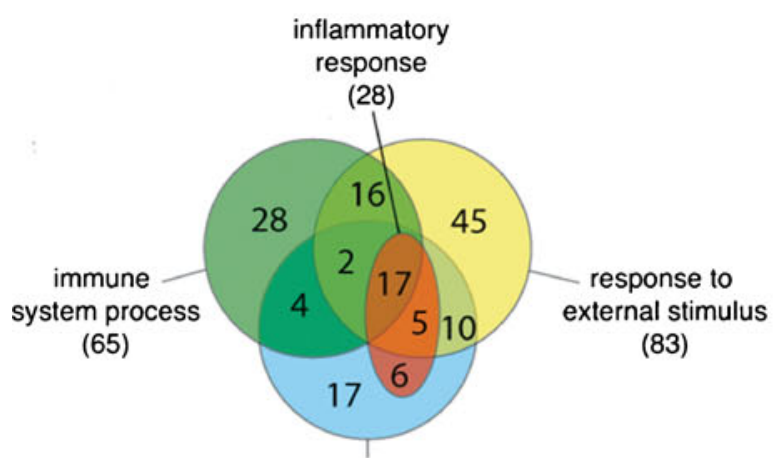

response to wounding

(55)

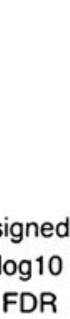

B

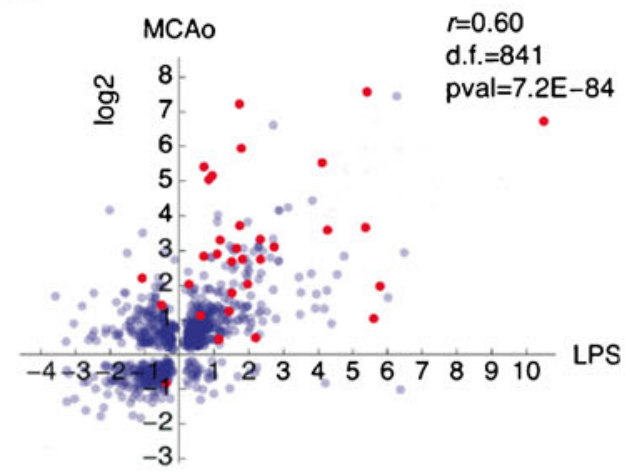

signed

$\log 10$

FDR

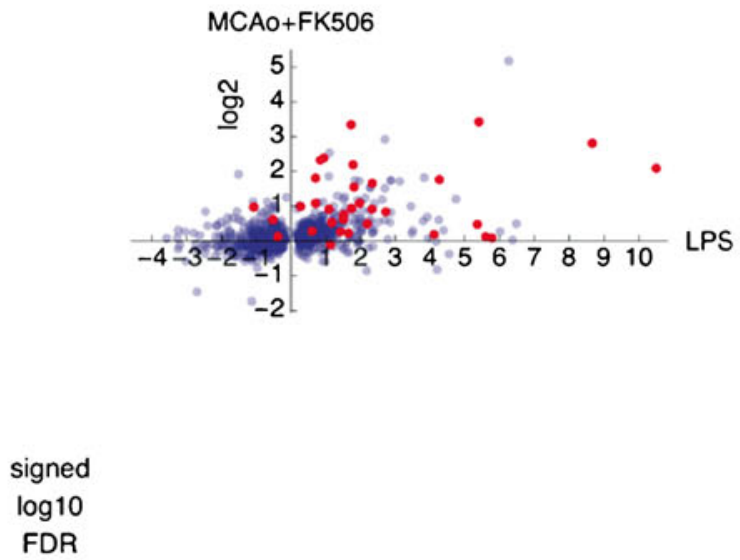

D GO: inflammatory response

GO: response to wounding

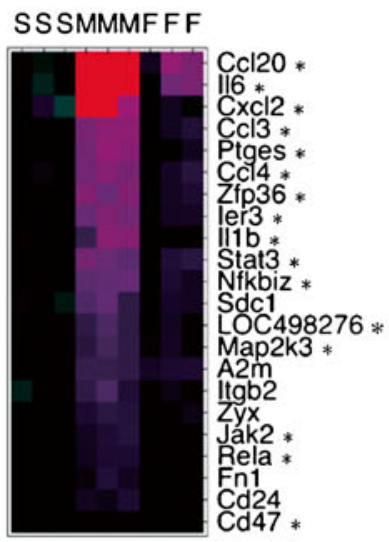

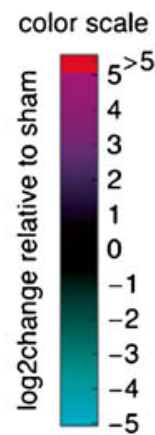

SSSMMMFFF

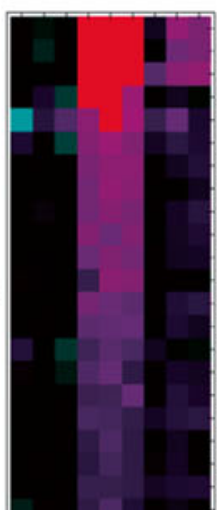

$\mathrm{Ccl} 20$

$116 *$

Timp1

Serpinb2 *

Adm

Ptges *

$\mathrm{Ccl} 4 *$ *

Ztp $36 *$

ler3 *

II1 *

Stat3*

Nifkbiz *

Sdc1

Mmp3 *

Gfap

LOC 498276 .

Map2k3 *

A2m

Itgb2

Kीf6

Jun

Zyx

Jak2 *

Txnrd1

Reasp3

Cd24

Nfe24.

Arg1*

Adam 17 *

Ptpn12

Cisb

Acvil1
Clu

Pkm2

Cd47 * 131

Cst3

Stxbp3

Rab27a
P2ry12* 
induced upregulation of Cox-2 protein which corresponds to the results reporting lack of CsA effect on LPS-induced Cox-2 expression in human microglial cells [25]. Inhibition of Cox-2 activity, either genetically or pharmacologically, had neuroprotective effects in rodent models of stroke, possibly via suppression of inflammatory reactions [26].

Inhibition of numerous microglial functions by immunosuppressants suggests blocking the early steps of microglia activation. However, the most described mode of FK506 action is inhibition of calcineurin, the inhibitory effects of other signaling pathways have been described, exemplified by inhibition of MAPK signaling in lymphocytes. In most cells, including glial cells, inhibition of calcineurin signaling is achieved with $1 \mu \mathrm{M}$ CsA or FK506. As in LPS-stimulated microglia, the inhibitory effects are observed at $\geq 5 \mu \mathrm{M}$ CsA or FK506; we suggest that inhibition of calcineurin is not a triggering event and rather inhibition of MAPK signaling, that is an early event and partly dependent on chaperone functions of immunophilins, plays more important role.

Here, we demonstrate that FK506 reduced MAPK phosphorylation in LPS-treated microglia that may be a potential mechanism of drug action. MAP kinases mediate microglial responses to LPS, cytokines, and growth factors, and control production of inflammatory mediators. MAPK inhibitors act as anti-inflammatory drugs by reducing synthesis of inflammation mediators at multiple levels and blocking inflammatory cytokine signaling $[27,28]$. ERK, JNK, and p38 MAP kinases are activated by LPS in microglia and inhibition of a respective kinase with pharmacological inhibitors: CEP11004 or CEP-1347 reduced cytokine production in LPS-stimulated human and murine microglia cultures $[29,30]$ or exposed to neurotoxic peptide $A \beta 1-40$ [30]. SP6001, an inhibitor of JNK, reduced LPS-induced Cox-2, $T N F-\alpha, M I P-1$, and $I L-6$ expression, while inhibitors of ERK $1 / 2$ and $\mathrm{p} 38$ attenuated LPS-induced cell enlargement [31]. Our results find confirmation in recent data showing inhibition of JNK activity in FK506-treated animals that links the neuroprotective action of FK506 with JNK signaling [32]. The inhibitory effect of FK506 on MAPK signaling may explain complex action, both on initiation as well as on propagation of inflammatory responses in microglia. Small molecule inhibitors' targeting of p38 MAPK and JNK pathways showed a great potential as potent modulators of brain inflammation and gliosis in neurological disorders, where cytokine overproduction contributes to disease progression $[27,28,33]$. Inhibitors of p38 MAPK and ERK reduced IL- $1 \beta$ production, brain injury, and neurological deficits in cerebral focal ischemia $[34,35]$. Studies with MAPK inhibitors on microglial cultures revealed distinct roles of particular kinase in controlling specific events in microglial activation [31], suggesting that a cocktail of MAPK inhibitors would be required to block efficiently all microglial responses. We demonstrate that FK506, a well-known drug with good pharmacokinetics, efficiently blocks many functions of microglia: cell enlargement, migration, and production of inflammation mediators at clinically relevant concentrations offering a new opportunity for treatment of poststroke neuroinflammation.

Competing interests The authors declare that they have no competing interests.

Sources of funding This study was supported by grants NN401 0475 and PBZ/MEiN/01/2006/32 from the Polish Ministry of Science and Higher Education and PERG05-GA-2009-240705 from the FP7PEOPLE-2009-RG.

Open Access This article is distributed under the terms of the Creative Commons Attribution License which permits any use, distribution, and reproduction in any medium, provided the original author(s) and the source are credited.

\section{References}

1. Hanisch UK, Kettenmann H (2007) Microglia: active sensor and versatile effector cells in the normal and pathologic brain. Nat Neurosci 10:1387-1394

2. Aloisi F (2001) Immune function of microglia. Glia 36:165-179

3. Allan SM, Tyrrell PJ, Rothwell NJ (2005) Interleukin-1 and neuronal injury. Nat Rev Immunol 5:629-640

4. Loddick SA, Rothwell NJ (1999) Mechanisms of tumor necrosis factor alpha action on neurodegeneration: interaction with insulinlike growth factor-1. Proc Natl Acad Sci U S A 96:9449-9451

5. Simi A, Tsakiri N, Wang P, Rothwell NJ (2007) Interleukin-1 and inflammatory neurodegeneration. Biochem Soc Trans 35:1122-1126

6. Kaminska B, Gaweda-Walerych K, Zawadzka M (2004) Molecular mechanisms of neuroprotective action of immunosuppressantsfacts and hypotheses. J Cell Mol Med 8:45-58

7. Gold BG, Villafranca JE (2003) Neuroimmunophilin ligands: the development of novel neuroregenerative/neuroprotective compounds. Curr Top Med Chem 3:1368-1375

8. Macleod MR, O'Collins T, Horkey LL, Howells DW, Donnan GA (2005) Systematic review and metaanalysis of the efficacy of FK506 in experimental stroke. J Cereb Blood Flow Metab 25:713-721

9. Furuichi Y, Maeda M, Matsuoka N, Mutoh S, Yanagihara T (2007) Therapeutic time window of tacrolimus (FK506) in a nonhuman primate stroke model: comparison with tissue plasminogen activator. Exp Neurol 204:138-146

10. Furuichi Y, Noto T, Li JY, Oku T, Ishiye M, Moriguchi A, Aramori I, Matsuoka N, Mutoh S, Yanagihara T (2004) Multiple modes of action of tacrolimus (FK506) for neuroprotective action on ischemic damage after transient focal cerebral ischemia in rats. Brain Res 1014:120-130

11. Tsujikawa A, Ogura Y, Hiroshiba N, Miyamoto K, Kiryu J, Honda Y (1998) Tacrolimus (FK506) attenuates leukocyte accumulation after transient retinal ischemia. Stroke 29:1431-1437

12. Zawadzka M, Kaminska B (2005) A novel mechanism of FK506mediated neuroprotection: downregulation of cytokine expression in glial cells. Glia 49:36-51

13. Szydlowska K, Gozdz A, Dabrowski M, Zawadzka M, Kaminska B (2010) Prolonged activation of ERK triggers glutamate-induced 
apoptosis of astrocytes: neuroprotective effect of FK506. J Neurochem 113:904-918

14. Zawadzka M, Kaminska B (2003) Immunosuppressant FK506 affects multiple signaling pathways and modulates gene expression in astrocytes. Mol Cell Neurosci 22:202-209

15. Irizarry R, Gautier RL, Cope L (2002) An R package for analyses of affymetrix oligonucleotide arrays. In: The analysis of gene expression data: methods and software. Springer, New York

16. Storey JD, Tibshirani R (2003) Statistical significance for genomewide studies. Proc Natl Acad Sci U S A 100:9440-9445

17. Beissbarth T, Speed TP (2004) GOstat: find statistically overrepresented Gene Ontologies within a group of genes. Bioinformatics 20:1464-1465

18. Kaminska B, Gozdz A, Zawadzka M, Ellert-Miklaszewska A, Lipko M (2009) MAPK signal transduction underlying brain inflammation and gliosis as therapeutic target. Anat Rec 292:1902-1913

19. Beuscher HU, Gunther C, Rollinghoff M (1990) IL-1 $\beta$ is secreted by activated murine macrophages as biologically inactive precursor. J Immunol 144:2179-2183

20. Denes A, Pinteaux E, Rothwell NJ, Allan SM (2011) Interleukin-1 and stroke: biomarker, harbinger of damage, and therapeutic target. Cerebrovasc Dis 32:517-527

21. Attur MG, Patel R, Thakker G, Vyas P, Levartovsky D, Patel P, Naqvi S, Raza R, Patel K, Abramson D et al (2000) Differential antiinflammatory effects of immunosuppressive drugs: cyclosporin, rapamycin and FK-506 on inducible nitric oxide synthase, nitric oxide, cyclooxygenase-2 and PGE2 production. Inflamm Res 49:20-26

22. Dusting GJ, Akita K, Hickey H, Smith M, Gurevich V (1999) Cyclosporin A and tacrolimus (FK506) suppress expression of inducible nitric oxide synthase in vitro by different mechanisms. Br J Pharmacol 128:337-344

23. Hamalainen M, Lahti A, Moilanen E (2002) Calcineurin inhibitors, cyclosporin A and tacrolimus inhibit expression of inducible nitric oxide synthase in colon epithelial and macrophage cell lines. Eur J Pharmacol 448:239-244

24. Strestikova P, Otova B, Filipec M, Masek K, Farghali H (2001) Different mechanisms in inhibition of rat macrophage nitric oxide synthase expression by FK 506 and cyclosporin A. Immunopharmacol Immunotoxicol 23:67-74

25. Choi HB, Khoo C, Ryu JK, van Breemen E, Kim SU, McLarnon JG (2002) Inhibition of lipopolysaccharide-induced cyclooxygenase-2, tumor necrosis factor-alpha and [Ca2+]i responses in human microglia by the peripheral benzodiazepine receptor ligand PK11195. J Neurochem 83:546-555

26. Minghetti L (2004) Cyclooxygenase-2 (COX-2) in inflammatory and degenerative brain diseases. J Neuropathol Exp Neurol 63:901-910

27. Kumar S, Boehm J, Lee JC (2003) p38 MAP kinases: key signalling molecules as therapeutic targets for inflammatory diseases. Nat Rev Drug Discov 2:717-726

28. Kaminska B (2005) MAPK signalling pathways as molecular targets for anti-inflammatory therapy-from molecular mechanisms to therapeutic benefits. Biochim Biophys Acta Proteomics 1754:253-262

29. Hidding U, Mielke K, Waetzig V, Brecht S, Hanisch U, Behrens A, Wagner E, Herdegen T (2002) The c-Jun N-terminal kinases in cerebral microglia: immunological functions in the brain. Biochem Pharmacol 64:781-788

30. Lund S, Porzgen P, Mortensen AL, Hasseldam H, BozyczkoCoyne D, Morath S, Hartung T, Bianchi M, Ghezzi P, Bsibsi M et al (2005) Inhibition of microglial inflammation by the MLK inhibitor CEP-1347. J Neurochem 92:1439-1451

31. Waetzig V, Czeloth K, Hidding U, Mielke K, Kanzow M, Brecht S, Goetz M, Lucius R, Herdegen T, Hanisch UK (2005) c-Jun Nterminal kinases (JNKs) mediate pro-inflammatory actions of microglia. Glia 50:235-246

32. Brecht S, Waetzig V, Hidding U, Hanisch UK, Walther M, Herdegen T, Neiss WF (2009) FK506 protects against various immune responses and secondary degeneration following cerebral ischemia. Anat Rec 292:1993-2001

33. Kaminska B, Swiatek-Machado K (2008) Targeting signaling pathways with small molecules to treat autoimmune disorders. Expert Rev Clin Immunolog 4:93-112

34. Barone FC, Irving EA, Ray AM, Lee JC, Kassis S, Kumar S, Badger AM, White RF, McVey MJ, Legos JJ et al (2001) SB 239063, a second-generation p38 mitogen-activated protein kinase inhibitor, reduces brain injury and neurological deficits in cerebral focal ischemia. J Pharmacol Exp Ther 296:312-321

35. Piao CS, Kim JB, Han PL, Lee JK (2003) Administration of the p38 MAPK inhibitor SB203580 affords brain protection with a wide therapeutic window against focal ischemic insult. J Neurosci Res 73:537-544 